\title{
Online Identities: National and Cultural Expression Online, an Australian Perspective
}

\author{
Celia Lam ${ }^{1}$ \\ ${ }^{1}$ School of Arts and Sciences, The University of Notre Dame Australia, Sydney, Australia \\ Correspondence: Dr Celia Lam, School of Arts and Sciences, The University of Notre Dame Australia, Sydney \\ Campus, 104 Broadway Broadway, NSW, 2007 Australia. E-mail: celia.lam@nd.edu.au
}

Received: December 20, 2012 Accepted: January 11, 2013 Available online: April 26, 2013

doi:10.11114/smc.v1i1.29 URL: http://dx.doi.org/10.11114/smc.v1i1.29

\begin{abstract}
Over the last decade the genesis and use of Social Networking Sites (SNS) has steadily gained traction with the almost instant popularity of sites such as Youtube, Facebook, Cyworld and Twitter to name a few. In Australia, as in the rest of the developed and developing world, Social Media (SM) use has become an integral part of the communication, entertainment and media practices of large sections of the population, with participation in online communities often employing the same social capital and patterns of communication that occur in offline encounters. Online interaction in SNS necessitates the creation of an individual's online identity, and with it notions of representation and group-affiliation come to the fore. The policy of multiculturalism in Australia encourages the interaction of minority (ethnic) Cultural identities with the dominant (national) Australian identity. This study examines the role online interaction plays in an individual's engagement with these two notions of identity by focusing on the SM use of students at a University in Australia. Results reveal a highly nuanced expression of self-hood where National and Cultural identities are enacted as minor components of a holistic Personal online identity.
\end{abstract}

Keywords: online identity, expression, ethnic, national, multiculturalism, Australia

\section{Introduction}

The National Identity of a nation is a complex and fluid concept that encounters expressions of ideology and social behavior, and engages with socio-political notions of nation, society and ethnicity. Broadly speaking a nation is described as "a group of people who feel themselves to be a community bound together by ties of history, culture and common ancestry" (Kellas, 1991, p.3). However within that distinction the multiplicities of culture, history and socio-political outlook often co-existing in contemporary society is accounted for by the definition of 'official nation[s]', the politically constructed nation-state, 'ethnic nation[s]', a nation formed of one ethnic group, and the collection of several ethnic groups that form a 'social nation' (Kellas, 1991).

Within these distinctions, many nation-states can be confidently categorised as social nations operating under the political authority of an official nation, where ideas of National Identity can often be varied and conflicted. A cohesive sense of inclusion within a social group is encouraged by the articulation of a common identity with which all members of that group, or nation, can affiliate. For individuals, the very notion of identity invokes emotional, political and historical responses that may or may not align with the construction of a nation-state's national image. In such cases the act of identity expression becomes not one of affiliation and acceptance, but one of negotiation.

Online environments offer the individual the ability to engage with virtual communities (Diamandaki, 2003) that are geospatially disconnected but united through common interests and shared cultural experiences (Khvorostianov, Elias, and Nimrod, 2011, pp. 583-599). For migrants in particular, the importance of the virtual community has been highlighted where the Internet provides a method of communication and connection with other members of the diaspora allowing migrants to share information about the new society and retain cultural and social bonds from the country of origin (Diamandaki, 2003; Khvorostianov et al., 2011; Yuen, 2007, Xie, 2005).

Immigration has been a part of Australian history since the post war era, while policies of multiculturalism 
adopted in the 1970s have allowed for increases in migrant populations that directly shape Australia's social fabric today. The multitude of cultures currently co-existing in contemporary Australian society has provided a means for the interrogation of notions of Australian identity that is present in Australian politics and media. This study examines how the expressions of these notions of identity are manifest in, and influence, online identity construction in the student population of the University of Notre Dame Australia, Sydney Campus.

\subsection{Online Identity Construction}

Social media (SM) use is highly prolific in most developed and developing countries (Nielsen, 2010) and research has shown that online and offline interaction is highly integrated, (Barkhuss\&Tashiro, 2010, pp. 133-142) particularly in the youth-orientated college or university environments. Online identity construction in the majority of student bodies studied in the literature suggest the wish to present a social persona fully embedded in the social situations around them and connected to other individuals in their social circles (Boyle \& Johnson, 2010; Jung, Youn, and McClung, 2007; Pempek, Yermolayeva, and Calvert, 2009). The formation of a 'personal' (DiMicco\& Millen, 2007) self with the inclusion of information that more accurately reflects the offline self (Boyle \& Johnson, 2010, pp. 1392-1399), is most likely enacted by students in a university or college environment where close links between on and offline social interactions informs the construction of the online self. As students are likely to have face-to-face contact with others in their online network of friends, self-representation online is more closely aligned with the way in which the offline self is presented. In addition the social nature of the relationships formed in a student environment is more likely to encourage the posting of identity information that projects the image of a socially active and integrated individual.

Partly due to the non-anonymous (Zhao, Grasmuck, and Martin, 2008, pp. 1816-1838) nature of the sites as well as the social milieu in which they are utilised, Social Networking Sites (SNS) encourage a certain level of 'truthfulness' from the individual during the construction of online profiles, as well as during the interactions that take place in online platforms (Ellison, Heino, and Gibbs, 2006, pp. 415-441). Online social networks have created a series of environments where it has been suggested presentations of the 'true' (Ellison, et al., 2006, pp. 415-441) and 'ideal' (Higgins, 1987, pp. 319-340) selves are more easily facilitated. A side-effect of the highly visible nature of SNS such as Twitter and Facebook can often be to highlight the social behaviors of SNS users, including any ethno-racially motivated expressions of identity and interactions with other users in both on and offline scenarios. In a recent study of ethno-racial displays on the Facebook accounts of college students in the US, Grasmuck, Martin and Zhao (2009) found a distinct correlation between offline ethno-racial awareness and student organisation, and explicit online expression.

While it cannot be said that the university/college environment heightens awareness of ethno-racial alignments when compared to the rest of society, the stage of 'emerging adulthood' (Arnett, 2000, pp. 469-480) experienced by many individuals - wherein personal identities are consolidated and a greater examination of one's cultural identity/background occurs - during years of tertiary study could have an effect on such public displays of ethno-racial allegiance.

\subsubsection{Australian Perspective of Online Identity Construction to Date}

To date Australian perspectives on the study of online self-representation have focused on the study of discrepancies between on and offline representations of the self, specifically representations of 'idealised' selves online (Chester, 2004) and impression management of identities in online environments (Chester \&Bretherton, 2007, pp. 223-236). Researcher Kristy Young (2009, pp. 39-57) investigated identity creation on SNS through the lens of the socio-cultural education theories Situated cognition and Activity theory. She described an active integration of the online identities created by her subjects to the offline community in which they operated, where self-presentation and identity creation functioned as part of the 'learning' processes for online social interaction (Young, 2009, pp. 39-57). SNS were considered as tools in which socialisation practices online were learnt, enacted and passed on to the next generation by the individuals who used the sites.

Little study has been conducted from the perspective of the practical ways in which online identities are created. There has not been an attempt reported in the literature to identify the factors that contribute to the creation of Australian and Cultural Identities online. This current study focuses on how tertiary students, raised in a culturally pluralistic society such as Australia, accommodate and balance expressions of Cultural Identity concurrent to the dominant rhetoric of a National Australian Identity.

\subsection{National Identity in Australia}

Recent history in Australia has been shaped by a succession of new arrivals to the country that has changed and challenged the way in which its people perceive the nation. 


\subsubsection{Historical Perspectives}

The arrival of British settlers in the $18^{\text {th }}$ century marked the beginning of an uneasy relationship with the original inhabitants that continue to the present day. Initial attempts at accommodation and conciliatory co-existence soon gave way to animosity and open hostility when the expanding boarders of the new British settlements impinged on the existing territories and ways of living of Aboriginal Australians. The colonial administration imposed policies of 'protection' and assimilation when "it became clear the Aboriginal Australians were not destined to physical extinction" (Jones, 2000, pp. 175-186). Such policies resulted in the alienation of Aboriginal Australians from their culture and traditional lands.

It was not until the 1960s that Aboriginal activism sought to rectify some of this disenfranchisement by demanding equal rights, with land rights the championing cause of the movement. This ongoing action led to the 1967 amendment of the constitution of Australia limiting the power of State governments to pass legislation over Aboriginal peoples, and more recently to the Native Title Act (1992) (Australian Bureau of Statistics, 2006) that acknowledges the right of Aboriginal and Torres Strait Islander peoples to claim ownership over their traditional lands where continuous occupation could be demonstrated. The Act recognised the cultural connection between Aboriginal and Torres Strait Islander peoples and the land on which they resided, and effectively overturned the notion of Terra nullius (or 'empty land') (Australian Bureau of Statistics, 2006). In 2008, the then Prime Minister of Australia, Kevin Rudd officially apologised to the Indigenous peoples of Australia for what has been commonly termed the 'Stolen generation', a policy enacted in the 1950s whereby Aboriginal children were removed from their families and raised in white institutions or foster families (Australian Government Site, 2012).

Although conditions have improved of recent years Aboriginal levels of education, life expectancy and health still remain the lowest in Australia, making Aboriginal Australians the most disadvantaged group in Australian society (Jones, 2000, pp. 175-186). Tensions have risen within the last decade between the government and Aboriginal groups, with strong reactions to the Northern Territory Intervention introduced by the Howard government in 2007 and sustained by the Rudd-Gillard government to the present day (SBS World News Australia, 2011). While in 2012, activists from the Aboriginal Tent Embassy - a semi-permanent and controversial assembly self-proclaimed to represent the political rights of Aboriginal Australians - in Canberra clashed with police during heated protests outside a function hosting the heads of both major Australian political parties (Leslie, 2004). As such, Aboriginal Australia is often considered to be distinct from other manifestations of the Australian 'nation' (Jones, 2000, pp. 175-186) a divide considered by some to be an obstacle in the construction of a 'true' representation of Australia's National Identity.

\subsubsection{Immigration}

For much of its immigration history, Australia had identified with a British character, considering itself as a "New Britannia" (Jones, 2000, pp. 175-186) and promoting a population that was "98 per cent British" (White, 1979). While the establishment of gold mines attracted prospectors from Asian and South East Asian countries, up until the 1970s, immigration policy (commonly known as the White-Australia policy) (Commonwealth of Australia Immigration Site, 2011) generally discouraged non-British and later, non-European entries to Australia. 1973 marked the introduction of a multicultural immigration policy that, after several decades of changing migration patterns influenced by the Second World War and Vietnam War, signaled the end of a period of immigration history where non-British new comers were expected to conform to Anglo-British ways of life. New migrants were able to retain their traditions and culture while demonstrating a "commitment to the basic institutions of Australian society"(Jones, 2000, pp. 175-186).

As of the last national Census conducted in 2006, apart from the constituent countries of the United Kingdom (England, Northern Ireland, Scotland and Wales) and Irish, twenty-four nationalities were identified as nationalities of origin for Australian citizens (Australian Bureau of Statistics, 2006). Of non-European nationalities, Chinese $(2.64 \%)$, Indian $(0.92 \%)$, Lebanese $(0.72 \%)$ and Vietnamese $(0.68 \%)$ were listed as the four most populous groups. With further global unrest in African and Middle Eastern nations in the years since 2006, it is anticipated that the 2011 national Census (data not yet released at the time of writing) will reflect further shifts in nationalities of origin (Australian Bureau of Statistics, 2006).

In the relatively short period of time since the abolition of the White-Australia policy, the face of Australian society has dramatically changed from one that promoted a homogenous Anglo-British culture to one that aims to support the expression of multiple cultures. Within that socio-political framework the notion of a National Australian Identity, often associated with notions of egalitarianism and promoted as the 'Australian way', exists 
as a representation of mainstream identity. While there is an active recognition of the different cultures existing in Australia, new migrants are encouraged to embrace and engage with this National Identity and the 'Australian way', giving rise to the expectation of a co-existence of National and Cultural Identities practiced by Australians of multi-cultural backgrounds (Jones, 2000, pp. 175-186).

How individuals within the Australian society negotiate and balance the expression of National and Cultural Identities can often be hard to determine however the online behavior of individuals, specifically the way in which online identities are created, might give an insight into how young Australians who have grown up under the multicultural policy might express and balance these identities.

\subsection{Research Questions}

The study proposes the following three Research Questions:

R1: How do Australian youth consider the National Australian Identity to be expressed in online environments?

R2: How are individuals' Cultural identities expressed in online environments?

R3: How do Australian youth balance expressions of Cultural and National identities in online environments?

\section{Method}

\subsection{Procedure}

A pilot study was conducted at the Sydney campus of the University of Notre Dame Australia in the 2011 academic year. Students from the School of Arts and Sciences were invited to participate in the study by filling out a self-reported questionnaire. The questionnaire consisted of questions relating to the representation of Cultural identity in online environments and sought the participants' opinions on the representation of the Australian National Identity online.

To ensure the largest number of respondents, the questionnaire was distributed during lectures where the entire cohort of a unit of study would be present. Consent was implied by a voluntary response to the questionnaire, and ethical clearance was granted by the HREC of the University of Notre Dame Australia.

\subsection{Assessment of National and Cultural Online Identity Expression}

Demographic information was collected on participants' age, sex, education and working status, the countries of origins of both parents, and self-perceived cultural background(s).

Attitudes towards what constituted the National Australia Identity in online environments were gauged using multiple-choice questions that asked respondents to choose as many items from a set list they felt to be the most representative of the Australian National Identity online. The list was determined by a group of SNS users trialed in a pilot survey. An 'other' option encouraged participants to state any items they felt were missing from the list.

Expressions of National Identity online were assessed using direct questions on whether 'Australian' artifacts were used in online identity construction. For positive responses, participants were asked to elaborate in free-form text why those artifacts were used. Negative responses were asked to expand on why the artifacts were not used. Manifestations of National Identity in online interaction were also examined using direct questions on whether 'Australian' artifacts were used in online interactions. For positive responses participants were asked to elaborate in free-form text why those artifacts were used, while negative responses were asked to expand on why they were not used.

Expressions of Cultural Identity online were assessed using direct questions firstly on whether respondents identified with a culture different from their perception of the mainstream. For positive responses, participants were presented with a list of items and asked to select all items they felt were used to represent their culture in online environments. An 'other' option allowed participants to specify any items they felt were missing from the list. Participants were then asked a direct question on whether any culturally specific artifacts were used during the creation of their online identities. Positive responses were asked to expand on what was used and why it was used. Online interaction using culturally specific artifacts was assessed with a direct question, with positive respondents asked to expand on why the artifacts were used. Negative responses were asked to expand on why culturally specific artifacts were not used.

\subsection{Analysis}

Data were analysed using mixed method analysis combining quantitative and qualitative analysis. Quantitative data were analysed using the SPSS V.18.0 software using percentage analysis to provide basic descriptive statistics on variables of interest. Results are summarised in table $1-4$. 
Qualitative responses were analysed using a thematic approach. Free form answers were collected from twelve questions incorporated into the questionnaire. Responses to the questions were tabulated according to two areas of interest, namely: Australian Online Identity construction and interaction, and Cultural Online Identity construction and interaction. Three categories were identified from the responses, specifically: Australian/Culturally specific artifacts; reasons for artifact use; reasons against artifact use.

After reading through the free form answers written responses were extracted according to common thematic traits arising from each category. The traits, and the frequency of each occurrence, were tabulated according to each category and summarised in tables $5-8$.

\section{Results}

One hundred and twenty nine students were recruited into the study with all respondents providing useful information on the questionnaire. Of the 129 , the majority were female $(\mathrm{n}=100,78 \%), 114$ were under the age of $23(\mathrm{n}=114,88 \%), 33 \%(\mathrm{n}=42)$ identified themselves to be from a Mainstream Australian cultural background, 37 (29\%) from a European background, and $16(\mathrm{n}=16,13 \%)$ reported to be from an Asian background. Other cultural backgrounds reported included African, South American, Mediterranean, Middle Eastern, and Pacific/Oceanic.

When asked about their paternal ancestry, or the region of the world from which their fathers originated, the majority $(n=57,45 \%)$ identified Europe as the region of origin, $10 \%(n=13)$ identified Asia, $11(9 \%)$ students the Mediterranean and $10(8 \%)$ nominated the Pacific/Oceanic region as their paternal region of origin.

Table 1. Demographics (N=129)

\begin{tabular}{|c|c|c|}
\hline Demographics & Frequency & Percentage \\
\hline \multicolumn{3}{|l|}{$\operatorname{Sex}(n=129)$} \\
\hline Male & 29 & $22 \%$ \\
\hline Female & 100 & $78 \%$ \\
\hline \multicolumn{3}{|l|}{ Age (years) $(n=129)$} \\
\hline $18-19$ & 53 & $41 \%$ \\
\hline $20-22$ & 61 & $47 \%$ \\
\hline 23 or older & 15 & $12 \%$ \\
\hline \multicolumn{3}{|c|}{ Cultural Background (self) $(n=129)$} \\
\hline African & 4 & $3 \%$ \\
\hline Asian & 16 & $13 \%$ \\
\hline European & 37 & $29 \%$ \\
\hline Mainstream Australian & 42 & $33 \%$ \\
\hline Mediterranean & 5 & $4 \%$ \\
\hline Middle East & 5 & $4 \%$ \\
\hline North American & 2 & $1 \%$ \\
\hline Pacific/Oceanic & 4 & $3 \%$ \\
\hline South American & 3 & $2 \%$ \\
\hline Mixed & 11 & $8 \%$ \\
\hline \multicolumn{3}{|c|}{ Paternal region of origin $(n=129)$} \\
\hline African & 7 & $5 \%$ \\
\hline Americas & 4 & $3 \%$ \\
\hline Asia & 13 & $10 \%$ \\
\hline Australia/non-specific & 13 & $10 \%$ \\
\hline European & 57 & $45 \%$ \\
\hline Mediterranean & 11 & $9 \%$ \\
\hline Middle East & 7 & $5 \%$ \\
\hline Pacific/Oceanic & 10 & $8 \%$ \\
\hline Mixed & 4 & $3 \%$ \\
\hline Unknown & 3 & $2 \%$ \\
\hline \multicolumn{3}{|c|}{ Maternal region of origin $(n=127)$} \\
\hline African & 6 & $5 \%$ \\
\hline Americas & 6 & $5 \%$ \\
\hline Asia & 14 & $11 \%$ \\
\hline
\end{tabular}




\begin{tabular}{lcl}
\hline Australia/non-specific & 14 & $11 \%$ \\
European & 54 & $43 \%$ \\
Mediterranean & 11 & $9 \%$ \\
Middle East & 5 & $4 \%$ \\
Pacific/Oceanic & 11 & $9 \%$ \\
Mixed & 5 & $4 \%$ \\
Unknown & 1 & $0.7 \%$ \\
\hline
\end{tabular}

Similarly, of 127 who responded, 54 (43\%) respondents identified Europe as the maternal region of origin. Asia was reported by $11 \%(\mathrm{n}=14)$ of participants, while the Mediterranean and Pacific/Oceanic region both constituted $9 \%(\mathrm{n}=11)$ of responses.

\subsection{Quantitative Analysis Results}

In response to the first research question (R1), namely how Australian youth consider the National Australian Identity to be expressed in online environments, 442 Australian artifacts were identified. Of the total, 70 (16\%) students identified the Sydney Harbour Bridge as being representational of the Australian Identity online, 57 (13\%) identified BBQs, $12 \%(\mathrm{n}=55)$ reported the Australian Flag, and 12\% ( $\mathrm{n}=55)$ also identified the Koala and Kangaroos as online representations of the Australian Identity.

Table 2. Representation of Australian National Identity online ( $\mathrm{N}=442)$

\begin{tabular}{lcc}
\hline \multicolumn{1}{c}{ Australian Artifact } & Frequency & Percentage \\
\hline $\begin{array}{l}\text { Representation of Australian National Identity } \\
\text { online (n=442) }\end{array}$ & \\
ACDC & 13 & $3 \%$ \\
Australian Flag & 55 & $12 \%$ \\
Barrier Reef & 29 & $7 \%$ \\
Barbeque & 57 & $13 \%$ \\
Boxing Kangaroo & 18 & $4 \%$ \\
Bridge & 70 & $16 \%$ \\
Crocodile Dundee & 32 & $7 \%$ \\
Koala/Kangaroo & 55 & $12 \%$ \\
Surfboard & 46 & $11 \%$ \\
Uluru/Outback & 45 & $10 \%$ \\
Other & 22 & $5 \%$ \\
\hline
\end{tabular}

The second research question (R2) addressed how Cultural Identities were expressed online. Seventy-four (57\%) students indicated that they identified with a culture other than the mainstream and of the 74,317 ways of online cultural representation were nominated. The majority reported film and TV ( $\mathrm{n}=57,18 \%), 52(16 \%)$ music, 15\% $(n=46)$ cultural attire, and $37(12 \%)$ reported food and drink to be representative of their culture online.

Table 3. Representation of Cultural Identity online $(\mathrm{N}=317)$

\begin{tabular}{lcc}
\hline \multicolumn{1}{c}{ Cultural Artifact } & Frequency & Percentage \\
\hline $\begin{array}{l}\text { Representation of Cultural Identity online } \\
(\mathrm{n}=317)\end{array}$ & & \\
$\quad$ Cultural attire & 46 & $15 \%$ \\
Colour scheme & 10 & $3 \%$ \\
Film TV & 57 & $18 \%$ \\
Flags & 15 & $5 \%$ \\
Food Drink & 37 & $12 \%$ \\
Icons & 15 & $5 \%$ \\
Images of people & 21 & $7 \%$ \\
Images of landscapes & 25 & $8 \%$ \\
Music & 52 & $16 \%$ \\
Sport & 25 & $8 \%$ \\
Text & 10 & $3 \%$ \\
\hline
\end{tabular}


Other 4 $1 \%$

In response to the question (R3) on how Australian youth balanced expressions of Cultural and National Identities online, $106(82 \%)$ of the total responses reported using Australian artifacts when creating online identities, while $57 \%(n=73)$ used Australian artifacts when interacting with others online. As reported a majority of $74(57 \%)$ students reported to identify with a culture other than the mainstream Australian culture. Of that 74, $50 \%(n=37)$ reported to use artifacts specific to their culture when creating their online identities and $44(59 \%)$ used cultural artifacts as part of their online interaction.

Table 4. Use of Australian, Cultural Artifacts online

\begin{tabular}{lcc}
\hline \multicolumn{1}{c}{ Online Creation/Interaction } & Frequency & Percentage \\
\hline $\begin{array}{l}\text { Australian artifacts Online }(\mathrm{n}=129) \\
\text { Online Identity Creation }\end{array}$ & & \\
$\quad$ Yes & 106 & $82 \%$ \\
$\quad$ No & 23 & $18 \%$ \\
\hline Online Interaction & 56 & \\
$\quad$ Yes & 73 & $43 \%$ \\
No $\quad$ & $57 \%$ \\
\hline Cultural artifacts Online $(\mathrm{n}=74)$ & 37 & \\
Online Identity Creation & 37 & $50 \%$ \\
$\quad$ Yes & & \\
$\quad$ No & & \\
\hline Online Interaction & 44 & $59 \%$ \\
$\quad$ Yes & 30 & $41 \%$ \\
$\quad$ No & & \\
\hline
\end{tabular}

\subsection{Qualitative Analysis Results}

Thematic analysis of the qualitative data produced results pertinent to R2 and R3. Of the 37 students who used culturally specific artifacts when creating their online identities, 30 (81\%) elaborated on the types of artifacts used. Photographs and pictures were the most frequently used artifacts $(n=11,37 \%)$, with $23 \%(n=7)$ reporting the use of language, and $3(10 \%)$ instances of cultural attire and music respectively. When asked why these cultural artifacts were used in their online identity construction, $24(65 \%)$ students responded with the majority $(n=11,46 \%)$ reporting that as their culture was representational of their sense of self, culturally specific artifacts were used in the construction of their online identities. Interest $(n=5,21 \%)$ and Ease of Communication $(n=3$, $13 \%$ ) were the next most frequently reported reasons for the use of cultural artifacts in online identity construction.

Table 5. Use of Cultural Artifacts in Online Identity Creation

\begin{tabular}{lcc}
\hline \multicolumn{1}{c}{ Cultural Artifacts } & Frequency & Percentage \\
\hline Cultural artifacts used in online ID & & \\
construction (n=30) & 11 & $37 \%$ \\
$\quad$ Photos/pictures & 7 & $23 \%$ \\
Language & 3 & $10 \%$ \\
Cultural attire & 3 & $10 \%$ \\
Music & 2 & $7 \%$ \\
Interests/Like pages & 2 & $7 \%$ \\
Following events of (sub) culture & 1 & $3 \%$ \\
Videos & 1 & $3 \%$ \\
Text & & \\
\hline Cultural artifacts reason for use in online ID & & \\
construction (n=24) & 11 & $46 \%$ \\
Representational of self & 5 & $21 \%$ \\
For interest & 3 & $13 \%$ \\
Ease of communication & & \\
\hline
\end{tabular}




\begin{tabular}{lcc}
\hline Cultural pride & 2 & $8 \%$ \\
Ease of interaction & 2 & $8 \%$ \\
Fun & 1 & $4 \%$ \\
\hline Cultural artifacts reason against use in online & & \\
ID construction (n=33) & & \\
$\quad$ Not necessary/relevant & 14 & $42 \%$ \\
$\quad$ Don't think about it/no reason to & 6 & $18 \%$ \\
Representation of self not related to & 4 & $12 \%$ \\
'Cultural' identity & & \\
Known by people offline & 3 & $9 \%$ \\
Privacy & 1 & $3 \%$ \\
Other & 5 & $15 \%$ \\
\hline
\end{tabular}

As far as the use of Australian artifacts in online identity construction, of the $106(82 \%)$ students from the total sample who reported using Australian artifacts to construction their online profiles, 22 (21\%) expanded on what artifacts were used. The most frequently used artifacts were photographs $(n=6,27 \%)$ that depicted Australia, followed by the use of Australian slang/language ( $n=5,23 \%)$, and $3(14 \%)$ reported the use of Australian humour. From the total sample, $89(69 \%)$ students detailed their reasons for not using Australian artifacts. Most respondents $(n=18,20 \%)$ did not find the need to advertise their 'Australian-ness' online, $17 \%(n=15)$ found it irrelevant or unnecessary, $14(16 \%)$ did not identify with Australia and 10\% (n=9) reported that their sense of self was not related to their Australian Identity.

Table 6. Use of Australian Artifacts in Online Identity Creation

\begin{tabular}{|c|c|c|}
\hline Australian Artifacts & Frequency & Percentage \\
\hline \multicolumn{3}{|l|}{$\begin{array}{l}\text { Australian artifacts used in online ID construction } \\
(\mathrm{n}=22)\end{array}$} \\
\hline Use of photos & 6 & $27 \%$ \\
\hline Use of slang/language & 5 & $23 \%$ \\
\hline Use of humour & 3 & $14 \%$ \\
\hline Location set to Australia & 2 & $6 \%$ \\
\hline Location - map & 1 & $5 \%$ \\
\hline 'Like' Australian online groups & 1 & $5 \%$ \\
\hline Reference to sport & 1 & $5 \%$ \\
\hline Reference to politics & 1 & $5 \%$ \\
\hline Advertise Australian identity & 1 & $5 \%$ \\
\hline Demonstrate an Australian attitude & 1 & $5 \%$ \\
\hline \multicolumn{3}{|l|}{$\begin{array}{l}\text { Australian artifacts reason for use in online ID } \\
\text { construction }(n=21)\end{array}$} \\
\hline Representational of self & 7 & $33 \%$ \\
\hline Celebrate/share Australia & 4 & $19 \%$ \\
\hline National pride & 4 & $19 \%$ \\
\hline Representational of country of residence & 2 & $10 \%$ \\
\hline Upbringing & 1 & $5 \%$ \\
\hline Other & 3 & $14 \%$ \\
\hline \multicolumn{3}{|l|}{$\begin{array}{l}\text { Australian artifacts reason against use in online } \\
\text { ID construction }(n=89)\end{array}$} \\
\hline No need to advertise Australian-ness & 18 & $20 \%$ \\
\hline No need/irrelevant & 15 & $17 \%$ \\
\hline Don't identify with Australia & 14 & $16 \%$ \\
\hline $\begin{array}{l}\text { Representation of self not related to } \\
\text { 'Australian' identity }\end{array}$ & 9 & $10 \%$ \\
\hline Known by people offline & 6 & $7 \%$ \\
\hline Don't think to & 6 & $7 \%$ \\
\hline Tacky & 4 & $4 \%$ \\
\hline Privacy/personal & 3 & $3 \%$ \\
\hline Not part of SM use & 1 & $1 \%$ \\
\hline Limited SM use/Limited information online & 1 & $1 \%$ \\
\hline
\end{tabular}


Other 12 $13 \%$

When asked about the use of Australian and Cultural artifacts in online interaction $56 \%$ ( $=72$ ) of the total responses, and $41 \%(n=30)$ of the participants identifying with a culture other than the mainstream reported using Australian and Cultural artifacts in their online interaction respectively.

Eighty six percent $(n=63)$ of the students who reported using Australian artifacts in online interactions listed reasons for their use, with $14(22 \%)$ responses stating it was natural to do so, $18 \%(\mathrm{n}=11)$ felt the artifacts reflected information about themselves, $9(14 \%)$ reported the artifacts were a reflection of their personal selves, while $8(13 \%)$ felt the artifacts were used as part of their upbringing, with only $5(8 \%)$ using the artifacts to reflect their Australian culture. Thirty-nine students not reporting to use Australian artifacts detailed reasons against the use. Of those 39, 13\% $(n=5)$ felt it was irrelevant, $4(10 \%)$ found no need to advertise their 'Australian-ness' online, and 5\% ( $\mathrm{n}=2)$ of respondents did not use Australian artifacts in their online interaction as they were known by people offline, $5 \%(n=2)$ for privacy reasons, and $5 \%(n=2)$ because their representation of their selves were not related to an 'Australian' identity.

Table 7. Reasons for/against use of Australian Artifact in Online Interaction

\begin{tabular}{lcc}
\hline \multicolumn{1}{c}{ Australian Artifacts } & Frequency & Percentage \\
\hline $\begin{array}{l}\text { Australian artifacts reason for use in online Interaction } \\
\text { (n=63) }\end{array}$ & \\
Natural & 14 & $22 \%$ \\
Reflects information of self & 11 & $18 \%$ \\
Reflects personal self & 9 & $14 \%$ \\
Upbringing & 8 & $13 \%$ \\
Reflects culture & 5 & $8 \%$ \\
Humour & 4 & $6 \%$ \\
Ease of communication & 4 & $6 \%$ \\
No reason & 2 & $3 \%$ \\
Other & 6 & $10 \%$ \\
\hline Australian artifacts reason against use in online & & \\
Interaction (n=39) & & \\
Don't use Australian slang, use plain language & 7 & $18 \%$ \\
No need/irrelevant & 5 & $13 \%$ \\
No need to advertise Australian-ness & 4 & $10 \%$ \\
Known by people offline & 2 & $5 \%$ \\
Privacy/personal & 2 & $5 \%$ \\
Representation of self not related to 'Australian' & 2 & $5 \%$ \\
identity & & \\
Don't identify with Australia & 2 & $5 \%$ \\
Don't think to & 2 & $5 \%$ \\
Don't know/no reason & 4 & $10 \%$ \\
Not part of SM use & 1 & $3 \%$ \\
Other & 8 & \\
\hline
\end{tabular}

Of the participants reporting to identify with a culture other than the mainstream and who used culturally specific artifacts in their online interaction, $83 \%(n=25)$ responded to the free text questions. The majority $(n=11,44 \%)$ identified the representation of a sense of self as the main reason for using the artifacts, $4(16 \%)$ used the artifacts for fun, and $12 \%(n=3)$ found communication easier using culturally specific artifacts when interacting with others online.

Table 8. Reasons for/against use of Cultural Artifact in Online Interaction

\begin{tabular}{lcc}
\hline \multicolumn{1}{c}{ Cultural Artifacts } & Frequency & Percentage \\
\hline $\begin{array}{l}\text { Cultural artifacts reason for use in online } \\
\text { Interaction }(\mathrm{n}=25)\end{array}$ & & \\
Representational of self & 11 & $44 \%$ \\
\hline
\end{tabular}




\begin{tabular}{lcc}
\hline For fun & 4 & $16 \%$ \\
For interest & 3 & $12 \%$ \\
Ease of communication & 2 & $8 \%$ \\
Cultural pride & 1 & $4 \%$ \\
Ease of interaction & 1 & $4 \%$ \\
Other & 3 & $12 \%$ \\
\hline Cultural artifacts reason against use in online & & \\
Interaction (n=22) & & \\
Cultural aspect doesn't come up online & 4 & $18 \%$ \\
No need/Not important & 4 & $18 \%$ \\
Known by people offline & 4 & $18 \%$ \\
Don't think to/no reason & 3 & $14 \%$ \\
No communication outside culture & 2 & $9 \%$ \\
Used only with family & 2 & $9 \%$ \\
Not part of SM use & 2 & $9 \%$ \\
Not comfortable to share & 1 & $5 \%$ \\
\hline
\end{tabular}

\section{Discussion}

\subsection{Cultural Identity}

The majority of students who participated in the study were below the age of 23 years of age, with many in their late teens. In development theory this is a period of 'emerging adulthood' (Arnett, 2000) where the declarations of religious, political and relationship preference that sparked the formation of a unique identity in the adolescent period is further refined with a deeper exploration of the self. Accompanying this exploration is a heightened awareness of ethnicity and, as Grasmuck et al describes in their study of College students in the US, "preoccupations about and heightened awareness of racial identities" (2009). Marcia (1989) describes how positive connections with diverse environments, or new communities, depends on the development of healthy cultural identities among young adults. With increasing trends in migration, the ability to retain or sustain cultural identities in culturally pluralistic societies becomes more complicated.

Grasmuck et al (2009) found a high level of explicit cultural narratives in the online behavior of their study cohort with reports of Latino, Black and Asian students more openly advertising their cultural allegiances than their white counterparts. Similarly Correa and Jeong (2011) reported students belonging to minority groups in the US Colleges they studied were more likely to engage in the creation of online content, while Byrne (2007) has suggested that participation in culturally motivated online forums has a positive effect on the racial identities of its participants. Unlike the studies reported in the US, the respondents from this study displayed a reluctance to engage in explicit expressions of Cultural identity in both their online identity construction and interaction.

On the whole, respondents used both visual (photos/picture, cultural attire) and aural (music) components of their online profiles to express their Cultural Identity while language was used to advertise cultural knowledge. While some students responded that their online behavior was directly motivated by a wish to advertise cultural pride and allegiance "I've like (sic) 'Mauritian' Fan pages to show that I'm a proud Mauritian." (Female participant, age range 20-22 years), the majority reported that Cultural expression was a by-product of their natural self-expression. A closer examination of the reasons behind the use of culturally specific artifacts in online identity construction revealed that most respondents used text and images in their profiles firstly as a result of a wish to portray aspects of their personalities, and that the artifacts were cultural in nature was often a result of its ability to represent a particular part of an individual's persona rather than as a representation of cultural allegiances per se. "Because it is more natural - identify with it better" (Female, age range 20-22 years).

In fact, Expression of Personality was one of three themes that emerged when investigating the motivations behind the use of culturally specific artifacts in online identity construction and online interaction. In 2011 Correa and Jeong identified Connection, Enacting the Self and Struggling as principles of online content creation, particularly among the minority groups of their study. This study identified trends of Communication, Expression of Personality and Social Organisation to be the main influences of participants' online identity construction and interaction.

\subsubsection{Communication}

Ease of communication with friends and family either overseas or from similar cultural backgrounds was widely 
reported as a main motivation for the use of particular languages and terminology in online interactions, as this 18-19 year old female respondent explains, "to communicate with my relatives who do not speak English".

Language, text and terminology from various sub-cultures act as a short hand way to engage in direct communication with others from similar backgrounds either locally or around the world. An individual possess a type of 'inside knowledge' of a different language system, cultural or political context, or hidden meanings in terms that is distinct from their normal, offline, forms of communication and uses this knowledge specifically in an online setting. Referring to images of the Italian chili on her online profile, this 20-22 year old participant expressed these sentiments; "I would put it up because its (sic) something that all Italians understand and I guess its (sic) about people being able to connect with me on the basis of my cultural background. Also it's a 'in the circle' kind of thing. So if you don't know what it is your (sic) not 'in' the circle of understanding."

Possessing such specific knowledge allows the individual to bridge the divide of distance by staying up to date with the latest developments in cultures/countries of origin and also enables them to seamlessly exchange ideas without the need for the translation that an 'outsider' would require. Additionally, the practice and use of their 'inside knowledge' enables individuals to develop feelings of group belonging with others who are equally adept at utilising the communication patterns and techniques of different culture, sub-cultures or common interest groups. Research into youth socialization has identified the importance that a sense of group belonging and connection with likeminded people plays in the social development of young people (Williams \&Thurlow, 2005), and highlighted the key role that SNS play in facilitating this social interaction in online environments (Joinson, 2008, pp. 1027-1036).

\subsubsection{Expression of Personality}

The use of culturally specific artifacts - images, sounds, text, cultural references - in both online identity construction and online interaction with others can often be an avenue for individuals to explicitly demonstrate or advertise cultural allegiances dependent on the extent to which these artifacts are used. Findings from the study Grasmuck et al (2009) conducted revealed students from cultural backgrounds were not only more likely to display their cultural allegiance through the use of images and music than their white counterparts, they were also more likely to join culturally motivated online groups, and to advertise this allegiance through references to their culture when interacting with others online.

Similar cultural artifacts were used by the participants in this study; with the use of photographs and language the most frequently reported. However the motivation behind the use revealed a desire for less explicit displays of cultural allegiance. Most respondents reported that the use of artifacts in the construction of online identities was an illustration of their 'personal' self rather than a representation of their culture. In the words of an 18-19 year old male participant, pictures from his culture are used in his online profile "because it's the way I represent who I'm (sic) and what my beliefs are."

For those respondents who did not use cultural elements in their online identity construction, the main reason stated was a wish to disassociate their online personas with any cultural connotations. Respondents either felt the use of cultural artifacts were not necessary or relevant $(n=14,43 \%)$, did not think to use such artifacts $(n=6,18 \%)$ or specifically stated their sense of self to be distinct from their cultural affiliations $(n=4,12 \%)$. When interacting online, $44 \%(\mathrm{n}=11,44 \%)$ of respondents stated that is was natural for them to use cultural artifacts as an organic process of self-representation. "Second nature" (female, age range 20-22 years) and "because it is part of my identity" (female, age range 20-22 years) are some responses typical of this sentiment.

\subsubsection{Social Organisation}

One 18-19 year old female participant outlined another reason for her lack of display of cultural artifacts online. "When you go online social networking there is no need to try and identify yourself with any culture. You go online to talk and organise events not to worry about culture" (Female participant, age range of 18-19 years). This sentiment is supportive of findings by Pempek et al (2009) that reported highly integrated SNS use in college students. SNS features such as the Calendar and Events functions on Facebook are used in conjunction with existing offline forms of communication such as texts and phone calls to organise social events and study related activities.

\subsubsection{Migration}

Some of the implicit behavior and propensity to display culture as a by-product of self expression is counter intuitive to the findings in the literature that suggest migrants find benefits in using online networks (Byrne, 2007), that minorities are more likely to engage in explicit ethno-racially motivated expression (Grasmuck et al, 2009) and are more likely to create online content (Correa \&Jeong, 2011, pp. 638-659). Reasons behind this are 
beyond the current scope of this study but could be attributed, in part, to the fact that unlike the Grasmuck et al (2009) study where there was high minority representation, the majority of students at the Notre Dame campus reported to identify with an Anglo-British background thereby creating an environment where explicit displays of migrant cultural identity is not the norm. Additionally, most respondents were third-fourth-and-fifth generation migrants and have developed the ability to inhabit Hall's two identities between 'tradition' and 'translation' (Hall, 1992). They are comfortable with the performance of culture associated with the mainstream culture, while enacting elements of their cultural heritage in ways they deem appropriate. A dual identity often created during the formative years of childhood. Further in depth research with migrants from various lengths of immigration would be prudent to illuminate this phenomenon further. Additionally the types of online sites visited by students from culturally diverse backgrounds needs to be studied in more detail to further investigate migrants' online identities.

\subsection{Australian Identity}

Evidence of similar trends were identified in the respondents who did not identify with a culture different from the mainstream. In general these respondents were from Anglo-British/European backgrounds and identified as Australian, however there was evidence of a reluctance to explicitly demonstrate or advertise this identity online.

Results indicate that participants responded to the more iconic imagery typically associated with Australia when considering the online representation of a National Identity. Possibly because the study was based in Sydney and thus participants had a heightened awareness of Sydney icons, the Sydney Harbour Bridge was selected as the most common response, while the popular social pastime of hosting a BBQ was selected as the second most common response. Other cultural icons such as Australia's native fauna, the beach lifestyle and the outback were also common responses. Surprisingly the Australian Flag was not reported as the most common representation of the Australian National Identity, and was tied third with Australian fauna. This could suggest that, at least in this particular cohort, the notion of a National Identity is more focused on cultural rather than political reflections of the nation.

When respondents were asked about the use of Australian artifacts in their online identities, the majority $(n=18$, 21\%) did not feel the need to advertise their Australian backgrounds. "I don't feel its (sic) necessary to create or use an Australian image because its (sic) obvious when you have your ethnicity as Australian or where you live as Australia" (Male participant within the age range of 20-22 years).

$10 \%$ also reported that their representation of self was not directly related to a specific Australian Identity. "I don't think I should have to show to people that I am Australian through such images like the Australian flag in order to convey who I am, because it only represent one aspect of who I am" (Female participant within the age range of 20-22 years).

In addition to the perception that any form of Australian Identity is only a component of a 'personal' identity, participants also displayed a wish to disassociate from perceived negative stereotypes. When asked why explicitly 'Australian' elements were not used in online identity creation or interaction, many respondents expressed sentiments similar to this 18-19 year old female respondent: "Because I don't see the need to promote my Australian-ism, plus I don't want to be seen as a bogan". The image of the 'typical' Australian as 'bogan' - a pejorative Australian slang describing an uneducated and uncouth individual - excessive beer drinkers and 'ocker', a variant of 'bogan' can be traced to the tourism campaigns in the 1980s that featured Crocodile Dundee actor Paul Hogan, beer can in hand inviting international visitors to "throw another shrimp on the barbie". Despite numerous updates, this 'ocker' image is still quite prevalent in international media representations today. Within Australia this representation is considered to be outdated and the dissonance between the secular cosmopolitan society and 80s throwback is seen as cringe-worthy.

It should be noted that all the participants in this survey were young and from urban parts of one state of Australia so these sentiments are not indicative of the society in general however the reluctance to advertise Australian-ness are supported by finding from the demographically representative Ipsos Mackay Report, Being Australian, conducted in 2011 and summarised in the newspaper publication, The Sydney Morning Herald. The report revealed a shift in 'traditional' Australian values in the twenty-three years since the last report was produced from a concern with hero-worshiping sportsmen and "reveling in a beer-soaked culture" (West, 2011) to one concerned with corporate greed, longer working hours and the impact of alcoholism (West, 2011).

The report also outlined an image of Australians who were "conflicted in their patriotism" (West, 2011). While participants believed that the boisterous pride associated with international sporting achievements, the "oi, oi, oi" patriotism", was increasing, there was evidence of a concern about excessive nationalism. "Some participants recoiled at the development of American-style patriotism in Australia; others accepted that for many indigenous 
Australians, Australia Day was "invasion day"” while others found the definition of a National Identity unique to Australia to be difficult (West, 2011).

\section{Conclusion}

This pilot study aims to examine current notions of Australian National Identity as is represented online, to investigate the creation and expression of Cultural Identities online and to explore how the Australian National Identity is balanced alongside expressions of Cultural Identity. As a pilot study a self-reflexive process of interrogation is also proposed to scrutinize the effectiveness of the survey-based study design.

Firstly, the research questions were successfully addressed through the study with viable results from the questionnaire, especially in response to R1. An analysis of the quantitative data reveals that the most commonly reported Australian artifact considered representative of the Australian National Identity online is the Sydney Harbour Bridge, revealing a more secular approach to the notion of National Identity. 23 participants reported to use Australian elements when creating their online profiles, while 73 acknowledged using Australian elements when interacting online.

In response to $\mathrm{R} 2$, results reveal that the majority $(\mathrm{n}=74,58 \%)$ of respondents report to identify with a culture other than mainstream Australian culture. Of these students, half used culturally specific elements when creating their online identities. Analysis of the free form text then revealed students' attitudes towards notions of Australian and Cultural identity to be less explicit than the ethno-racially motivated online behavior of the students in Grasmuck et al's (2009) US study. In general, students found concepts of Australian, and to a lesser extent Cultural, Identity to be limiting in terms of their definitions of the self. While acknowledged as concepts of identification, participants considered both Australian and Cultural Identities to be but one component of their personal selves (DiMicco \& Millen, 2007).

While there is insight into the ways in which online identities are created and enacted for participants identifying with Australian or Cultural Identities, less information is gained into the ways in which both Identities are balanced or negotiated. This can be attributed to a lack of detail garnered from the questionnaire. Questions on the intricacies of online interaction were difficult to quantify in the one-off written response of the survey-based design. To remedy this and to provide more information on behavior that can be quite nuanced, the incorporation of more in-depth focus groups would be beneficial. Face to face discussion on these topics would not only reveal more detailed information, but the reluctance of participants to put into writing sentiments that can often be delicate and easily misinterpreted can be overcome.

As with all studies this study had both strengths and weaknesses. The sample size, although small was indicative of the student cohort at the University of Notre Dame Australia and thus representational. As a pilot study the smaller sample size meant that the study could be conducted in one locality, and the numbers were sufficient to reveal significant results. As the Sydney campus is one of the smaller campuses of the University of Notre Dame Australia, the diversity of students is understandably lower than in larger campuses with higher student numbers. Future research should take into consideration the size of the campus and expand the study to other campuses of the University of Notre Dame and surrounding Universities to achieve more illuminating results. As mentioned, a change in the design of the study to include focus groups will also yield more nuanced results.

\section{References}

Arnett, J. J. (2000). Emerging adulthood: A theory of development from the late teens through the twenties. American Psychologist, 55, 469-480. http://dx.doi.org/10.1037/0003-066X.55.5.469

Australian Bureau of Statistics. (1995). The Mabo Case and the Native Title Act, Year Book Australia, Cat. No. 1301.0, June. Australia

Australian Bureau of Statistics. (2006). Census of Population and Housing Australia, Ancestry by Country of Birth of Parents for Time Series, Cat. No. 2068.0, June. Australia.

Australian Government. (2009). Sorry Day and the Stolen Generations. Retrieved from http://australia.gov.au/about-australia/australian-story/sorry-day-stolen-generations

Australian Government Department of Immigration and Citizenship. (2009). Fact Sheet 8 - Abolition of the White Australia Policy. Retrieved fromhttp://www.immi.gov.au/media/fact-sheets/08abolition.htm.

Barkhuss, L., \& Tashiro, J. (2010). Student Socialization in the Age of Facebook. In: Proceedings of CHI 2010 (pp.133-142), Atlanta, USA: ACM.

Boyle, K., \& Johnson, T. J. (2010). MySpace is your space?: Examining self-presentation of MySpace users. Computers in Human Behavior, 26, 1392-1399. http://dx.doi.org/10.1016/j.chb.2010.04.015 
Byrne, D. N. (2007). Public discourse, community concerns, and civic engagement: exploring black social networking traditions on BlackPlanet.com. Journal of Computer-Mediated Communication, 13(1), 319-340. http://dx.doi.org/10.1111/j.1083-6101.2007.00398.x

Chester, A. (2004). Presenting the self in cyberspace: Identity play in MOOS. Doctoral dissertation, University of Melbourne, Australia.

Chester, A., \& Bretherton, D. (2007). Impression management and identity online. In: A. Joinson, K. McKenna, T. Postmes, and U. D. Reip (Eds.),The Oxford Handbook of Internet Psychology (pp.233-236). Oxford: Oxford University Press.

Correa, T., \& Jeong, S. H., (2011). Race and online content creation. Information, Communication \& Society, 14(5), 638 - 659. http://dx.doi.org/10.1080/1369118X.2010.514355

Diamandaki, K. (2003). Virtual ethnicity and digital diasporas: Identity construction in cyberspace. Global Media Journal (American Edition), 2(2). Retrived from http://lass.purduecal.edu/cca/gmj/sp03/graduatesp03/gmj-sp03grad-diamandaki.htm

DiMicco, J. M., \& Millen, D. R. (2007). Identity Management: Multiple Presentations of Self in Facebook. In GROUP'07 Proceedings International ACM conference on Support group work, Florida, USA: ACM.

Ellison, N. B., Heino, R., \& Gibbs, L. (2006). Managing impressions online: Self-presentation processes in the online dating environment. Journal of Computer-Mediated Communication, 11, 415-441. http://dx.doi.org/10.1111/j.1083-6101.2006.00020.x

Ellison, N. B., Steinfield, C., \& Lampe. C. (2007). The benefits of Facebook "friends:" Social capital and college students' use of online social network sites. Journal of Computer-Mediated Communication, 12(4), 1143-1168. http://dx.doi.org/10.1111/j.1083-6101.2007.00367.x

Grasmuck, S., Martin, J., \& Zhao, S. (2009). Ethno-Racial Identity Displays on Facebook. Journal of Computer-Meditated Communication, 15, 158-188.http://dx.doi.org/10.1111/j.1083-6101.2009.01498.x

Hall. S. (1992). Introduction. In: S. Hall,\& B. Gieben (Eds.) Formation of Modernity. Cambridge: Polity Press.

Higgins, E. T. (1987). Self-discrepancy: A theory relating self and affect. Psychological Review, 94(3), 319-340. http://dx.doi.org/10.1037/0033-295X.94.3.319

Joinson, A. (2008). "Looking at", "looking up" or "keeping up with people"? Motives and uses of Facebook. In: CHI 2008 Proceedings: Online Social Networks, Association for Computer Machinery (pp.1027-1036), Florence, Italy: ACM.

Jones, F. L. (2000). Diversities of National Identity in a Multicultural Society: The Australian Case. National Identities, 2(2), 175-186. http://dx.doi.org/10.1080/713687690

Jung, T. H., Youn, H., \& McClung, S. (2007). Motivations and Self-Presentation Strategies on Korean-Based "Cyworld" Weblog Format Personal Homepages. Cyber Psychology \& Behavior, 10(1), 24-31. http://dx.doi.org/10.1089/cpb.2006.9996

Kellas, J. G. (1991). The Politics of Nationalism and Ethnicity. Houndmills: Macmillan Press Ltd.

Khvorostianov, N., Elias, N., \& Nimrod, G. (2011). 'Without it I am nothing': The internet in the lives of older immigrants. New Media \& Society, 14(4), 583-599. http://dx.doi.org/10.1177/1461444811421599

Leslie, T. (2012, Janurary 1). The History of the Aboriginal Tent Embassy. ABC News Online. Retrieved fromhttp://www.abc.net.au/news/2012-01-27/the-history-of-the-aboriginal-tent-embassy/3796630

Marcia, J. E. (1989). Identity and intervention. Journal of Adolescence, 12, 401-410. http://dx.doi.org/10.1016/0140-1971(89)90063-8

Nielsen Company. (2010, September 20). Global Audience Spends Two Hours More a Month on Social Networks than Last Year. Retrieved http://blog.nielsen.com/nielsenwire/global/global-audience-spends-two-hours-more-a-month-on-social-netw orks-than-last-year/

Pempek, T. A., Yermolayeva, Y. A., \& Calvert, S. (2009). College students' social networking experience on Facebook. Journal of Applied Developmental Psychology, 30, 227-238. http://dx.doi.org/10.1016/j.appdev.2008.12.010

SBS World News Australia. (2009). What is the Northern Territory Intervention. Retrieved from http://www.sbs.com.au/news/article/1027847/what-is-the-northern-territory-intervention 
West, A. (2011, June 25). Who do you think you are? The Sydney Morning Herald. Retrieved from http://www.smh.com.au/opinion/society-and-culture/who-do-you-think-you-are-20110624-1gjjh.html

White, R. (1979). The Australian Way of Life. Historical Studies, 18(73). http://dx.doi.org/10.1080/10314617908595612

Williams, A., \& Thurlow, C. (2005). Talking Adolescence: Perspectives on Communication in the Teenage Years. New York: Peter Lang.

Xie, W. J. (2005). Virtual space, real identity: Exploring cultural identity of Chinese Diaspora in virtual community. Telematics and Informatics, 22, 395-404. http://dx.doi.org/10.1016/j.tele.2004.11.006

Yuen, T., \& Byram, M. (2007). National identity, patriotism and studying politics in schools: a case study in Hong Kong. Compare: A Journal of Comparative and International Education, 37(1), $23-36$. http://dx.doi.org/10.1080/03057920601061729

Young, K. (2009). Online Social Networking: An Australian Perspective. International Journal of Emerging Technologies and Society, 7(1), 39-57.

Zhao, S., Grasmuck, S., \& Martin, J. (2008). Identity construction on Facebook: Digital empowerment in anchored relationships. Computers in Human Behavior, 24(5), 1816-1836. http://dx.doi.org/10.1016/j.chb.2008.02.012

\section{$(\mathrm{cc}) \mathrm{BY}$}

This work is licensed under a Creative Commons Attribution 3.0 License. 